\title{
The Necessity of Paying Attention to Assessment Tools of the Quality of Life of Afghan Immigrants Residing in Iran's Deprived Urban Areas
}

\author{
Mohammad Hossein Sorbi ${ }^{1}$, Shirin Yazdanpoor ${ }^{2}$, Reza Bidaki ${ }^{3,4, *}$ \\ ${ }^{1}$ Department of Psychology, Faculty of Medicine, Kermanshah University of Medical Science, Kermanshah, IR Iran \\ ${ }^{2}$ Department of Psychology, Malayer University, Hamadan, IR Iran \\ ${ }^{3}$ Research Center of Addiction and Behavioral Sciences, Shahid Sadoughi University of Medical Sciences, Yazd, IR Iran \\ ${ }^{4}$ Yazd Diabetes Research Center, Shahid Sadoughi University of Medical Sciences, Yazd, IR Iran
}

Corresponding Author: Reza Bidaki, MD. Psychiatrist, Associate Professor, Research Center of Addiction and Behavioral Sciences, Shahid Sadoughi University of Medical Sciences, Yazd, Iran. Email: reza_bidaki@ yahoo.com

Article History: Received: 18 Mar. 2016; Accepted: 25 Feb. 2016; Online Published: 25 Jun. 2016

Cite this article as: Sorbi MH, Yazdanpoor Sh, Bidaki R. The necessity of paying attention to assessment tools of the quality of life of afghan immigrants residing in Iran's deprived urban areas. Int J Travel Med Glob Health. 2016;4(2):71-2. doi: 10.20286/ijtmgh-04028

\section{Dear Editor}

The question of quality of life has attracted a lot of attention in recent years and is increasingly becoming the object of theoretical and empirical research in various disciplines. The study of such a concept is based on the fundamental assumption that the social and physical environment of an area can influence the well-being of people residing in that area [1]. Hence, measuring the quality of urban life in developed countries is one of the main purposes of urban studies which includes multiple biological, social, environmental, and economic components. Considering this indicator in cities is important as an efficient tool in urban management and planning and in determining the rate of community health $[1,2]$.

Iran as a developing country has high growth in urban population and in the number of cities. The urban population of the country (0.71.4) and the number of urban areas (up to 1331 areas) have increased according to 2011 statistics [3]. The total number of Afghan nationals in Iran in 2015 was about 2,500,000, about 1,000,000 of whom have been allowed to live in cities. At first glance, this figure seems to be insignificant, but those refugees and illegal immigrants who live in Iran and are unwilling to return to Afghanistan are deprived of many health and safety facilities for reasons of security, employment, and housing [4]. Most Afghan refugees have chosen to live in deprived urban areas that are unlike other urban areas in terms of the health reform and social-economic prosperity; moreover, the quality of life there is low. Studying and identifying the problems of immigrants in old and deprived areas in order to meet their health and security needs is crucial $[2,3]$.

Until now, few studies have investigated the quality of life in urban areas of Iran, particularly in deprived and old areas. Some studies have shown that no official investigation into the living conditions and access to health, comforts, and service facilities for Afghan immigrants has been done. Questions remain. Even though effective and necessary actions have been taken by the Interior Ministry to meet the needs of Afghan immigrants, are the satisfaction and quality of life of Afghan immigrants as long as they live in this country up to the standards of a community? Is there a significant difference in the quality of life of Afghan immigrants and citizens?
It should be noted that considering the quality of life of Afghan immigrants can encourage them to have an effective presence and promote health dimensions in their community and increase their sense of satisfaction with life [1]. It is recommended that the following international assessment strategies be used to improve the quality of life of Afghan immigrants in deprived areas:

1. Assessing Quality of Urban Life, developed by Doctor Fu (2008), has 14 and 18 indicators related to biological, psychological, social, and spiritual health, living conditions, and welfare services [5]. This tool is a good indicator of the ratio of health and safety facilities for a community, especially deprived areas.

2. The quality of life indicator developed by Lee in 2008 is a powerful tool for measuring biological and psychological health, housing, leisure and sports activities, community involvement, and holidays among people in a community [6].

3. Scientific research that examines the quality of urban life among Afghan immigrants and compares it with common urban lives should be conducted.

\section{Acknowledgments}

This paper has taken from Dr. Bidaki's ideas. The researchers thank Dr. Ahmadi and Ministry of Foreign Affairs of Yazd where have helped in collecting data.

\section{Authors' Contributions}

All authors contributed significantly towards the study.

\section{Financial Disclosure}

None.

\section{Funding/Support \\ None.}

\section{References}

1. Lambiri D, Biagi B, Royuela V. Quality of life in the economic and urban economic literature. Soc Indic Res. 2007;84(1):1-25. doi: 10.1007/s11205-006-9071-5

2. Smith C, Levermore G. Designing urban spaces and buildings to improve sustainability and quality of life in a warmer world. Energy Policy. 2008;36(12):4558-62. doi: 10.1016/j.enpol.2008.09.011

3. Pourahmad A, Zarei J. Measuring of quality of life in the realm of 
urban distressed areas: case studies in Tehran 9 district. J Res Urban Plan. 2015;21(9):1-18.

4. Mohammadian M, Dadfar M, Bolhari J, Karimi Keisami E Screening for mental disorders among Afghan immigrants residing in Tehran. Iran J Psychiatry Clin Psychol. 2005;11(3):270-7.
5. Seik FT. Subjective assessment of urban quality of life in Singapore (1997-1998). Habitat Int. 2000;24(1):31-49. doi: 10.1016/S01973975(99)00026-0

6. Lee Y-J. Subjective quality of life measurement in Taipei. Build Environ. 2008;43(7):1205-15. doi: 10.1016/j.buildenv.2006.11.023 